\title{
Research
}

\section{Perceived Benefits of Fisheries Management Restrictions in Madagascar}

\author{
$\underline{\text { Tim R. McClanahan }}{ }^{1}, \underline{\text { Joshua E. Cinner }}^{2}$, Caroline Abunge ${ }^{1}$, Ando Rabearisoa ${ }^{3}$, Paubert Mahatante ${ }^{4}$, Frederick Ramahatratra ${ }^{4}$ \\ and Norbert Andrianarivelo ${ }^{1}$
}

\begin{abstract}
Perceptions of the benefits of fisheries management restrictions were evaluated in coastal Madagascar to identify restrictions that are likely to be self- and community enforced. The survey focused on 24 Malagasy fishing villages adjacent to coral reefs. Resource users' perceptions of the benefits of restrictions were generally high and widespread, but some less positive perceptions were found in three villages located near marine protected areas. Perceptions of the benefits of gear restrictions had widespread support; closed areas, seasons, and minimum sizes of fish were less common; and restrictions on species were supported infrequently. We therefore advocate a management implementation approach that uses these scales of perceived benefits and prioritizes support for the most widely accepted restrictions most broadly, with the less accepted restrictions matched to specific supportive locations. At the village level, socioeconomic and wealth variables were not clearly associated with perceived benefits, which we suggest results from a stronger influence of village history than socioeconomic conditions. At the individual fisher level, however, there was evidence that experienced people involved in decision-making, having livelihood alternatives, and having permanent housing had more opinions and frequently were more supportive of management restrictions. Incorporating this information into forums and management plans is expected to increase the rate of adoption and compliance with needed fisheries restrictions.
\end{abstract}

Key Words: attitudes; fisheries management; marine protected area planning; poverty; social-ecological

\section{INTRODUCTION}

Getting resource users to comply with fisheries regulations is a considerable challenge for many marine resource management initiates. In many developing countries, fisheries managers are promoting better engagement with local resource users in an effort to develop regulations that better reflect local social, economic, and cultural conditions (Jentoft and Kristoffersen 1989, Pomeroy and Berkes 1997, Béné et al. 2009). It is expected that rules that are viewed as beneficial to local stakeholders and more locally appropriate are likely to be perceived as more legitimate in the eyes of resource users and be adopted and complied with (Ostrom 1990, Wade 1994). In particular, resource users are expected to comply with management restrictions that they perceive to be equitable, developed through legitimate processes, and beneficial to themselves (Sutinen and Kuperan 1999). In particular, when national-level legal governance and enforcement structures are weak, there will be even greater reliance on the local perceptions, the scale of benefits, and self- and community enforcement (McClanahan et al. 2008).

In practice and despite the need, getting resource users to agree on and develop rules can be extremely difficult. A broad body of theoretical and empirical research from both marine and terrestrial systems shows that there are often heterogeneous perceptions about the benefits and costs of various management strategies among different stakeholder groups (e.g., fishers, managers, tourism operators) and even within a single stakeholder group (e.g., fishers using different gear; Adams et al. 2003, McClanahan et al. 2008). Understanding this heterogeneity in users' perceptions of different management options and how it is related to key socioeconomic drivers such as poverty and migration can help to uncover potentially viable solutions or sources of conflict. Specifically, efforts to characterize users' perceptions about management can help: (1) to provide perceived legitimacy to the processes of rule development, (2) to identify particular management strategies that have broad support, and (3) to identify whether specific user groups may feel disenfranchised by a particular strategy. Using this knowledge in negotiations and management plans is expected to reduce the conflicts between resource users and managers and could potentially lead to faster implementation, higher rates of success, and more congenial and productive resource user-manager interactions.

Madagascar is a poor country that relies heavily on its coastal resources for consumption, trade, and tourism (Gabrié et al. 2000, Cooke 2003, Le Manach et al. 2012). Although quantitative information on the state of marine resources is sparse (Le Manach et al. 2012), many studies identify heavy and uncontrolled use, which is expected to benefit from increased management restrictions (Laroche et al. 1997, Nadon et al. 2007, Doukakis et al. 2008, Harris et al. 2010, Bruggemann et al. 2012, Le Manach et al. 2012). Proposals to increase management efforts and plans have been developed, for example, an extensive network of marine protected areas (Allnut et al. 2012), but the high costs of management are likely to result in a mix of multiple resource-use restrictions that will rely heavily on a mixture of outside support and legislation and local-level governance and enforcement (Rakotoson and Tanner 2006, Cinner et al. 2009c). For example, lack of funds and weak control of parks by the national government led to the creation of the nonprofit organization in 1990, Madagascar National Parks, which has the responsibility to manage protected areas and is recently funded almost entirely by international donor grants and trust funds (World Bank 2013). Further, the pre-colonial cultural social contract concept of dina is part of the country's legal framework and is used to develop local and customary regulations of natural resources. Consequently, modern management requires the challenging task of integrating modern legislation with traditional and emerging customs (Rakotoson and Tanner 2006). Recent papers describe the social and institutional aspects of transitions toward fisheries co-management (Cinner et al. 2009c, 2012a).

Resource management studies frequently uncover conflicts among managers, planners, and resource users regarding culture, 
perceptions, and the making and enforcement of rules at different levels of governance (Keller 2009). These conflicts have frequently resulted in low compliance and further resource degradation in forests (Horning 2005). Employment in the environment and fisheries management sector has always been very low in Madagascar and has declined further since the national governance crises in 2009 (World Bank 2013). Consequently, there has been and is very little on-the-ground presence of the national government in fisheries management. Consequently, to help develop the capacity for the emerging community-based management (Rakotoson and Tanner 2006, Cinner et al. 2012a), we undertook this study to evaluate the preferences of Malagasy fishers in coral reef areas that are likely to be a high priority for future management plans and associated restrictions, including marine protected areas. We specifically evaluated how fishers perceived benefits of restrictions to themselves and the socioeconomic correlates with these perceptions. Our intentions were to assist the creation of policies and management capable of rapid and successful implementation in which self- and community management are expected to be the main mechanisms of enforcement.

\section{Study region}

Madagascar has a long and varied coastline where the northeast and west sides support nearshore coral reefs that are important fishing locations (Gabrié et al. 2000, McClanahan et al. 2009). We studied 24 fishing villages located in eight districts in the major locations where fishing is undertaken on coral reefs (Fig. 1). These villages and districts represent different climatic and socialecological conditions, but all people depend heavily on natural resources. Rainfall and reliance on agriculture are key variables; rainfall is highest in the northeast followed by the northwest, and is very low in the southwest.

In the southwest region, some fishers engage in local and migratory fishing excursions and trade marine resources for key products such as rice (Iida 2005). They use traditional pirogues (3-8 $\mathrm{m}$ long) that have an outrigger and sail. The main types of fishing gear in use are line, gill net, beach seine, and spear gun. Studies in the southwest Ranobe area were carried out in four villages in 2008: Madiorano, Amboaboaky, Ambotsibotsike, and Ankilibe. An additional seven communities adjacent the Grande Recife of Toliar were studied during 2010. Two of the villages, Ankilibe and Sarodrano, are adjacent to the city of Toliara while the others are located in rural areas south of the city.

The northeast region of Antongil Bay contains a number of habitats, including estuaries, seagrass beds, mangroves, and coral reefs, and is a seasonal breeding habitat for humpback whale (Megaptera novaeangliae). Agriculture and fishing are key livelihood activities (Cinner et al. 2009b). A series of national marine protected areas was established in 1997 (Kremen et al. 1999, Cinner et al. 2009c), and a number of locally managed marine protected or management areas are being planned for the larger seascape. Local vigilance committees have been created to enforce the law on prohibited fishing gear. Nine villages were surveyed from this region in the three districts of Antalaha in the east, Maroantsetra in the north, and Mananara in the west.

The Ambaja district of the northwest region of Madagascar has a number of proposed management areas, including reefs in the region of Nosy Be, Nosy Komba, Nosy Sakatia, and Ambariotelo. Nosy Sakatia has a coral reef in front of
Fig. 1. Map of Madagascar indicating the locations of the fishing villages studied.

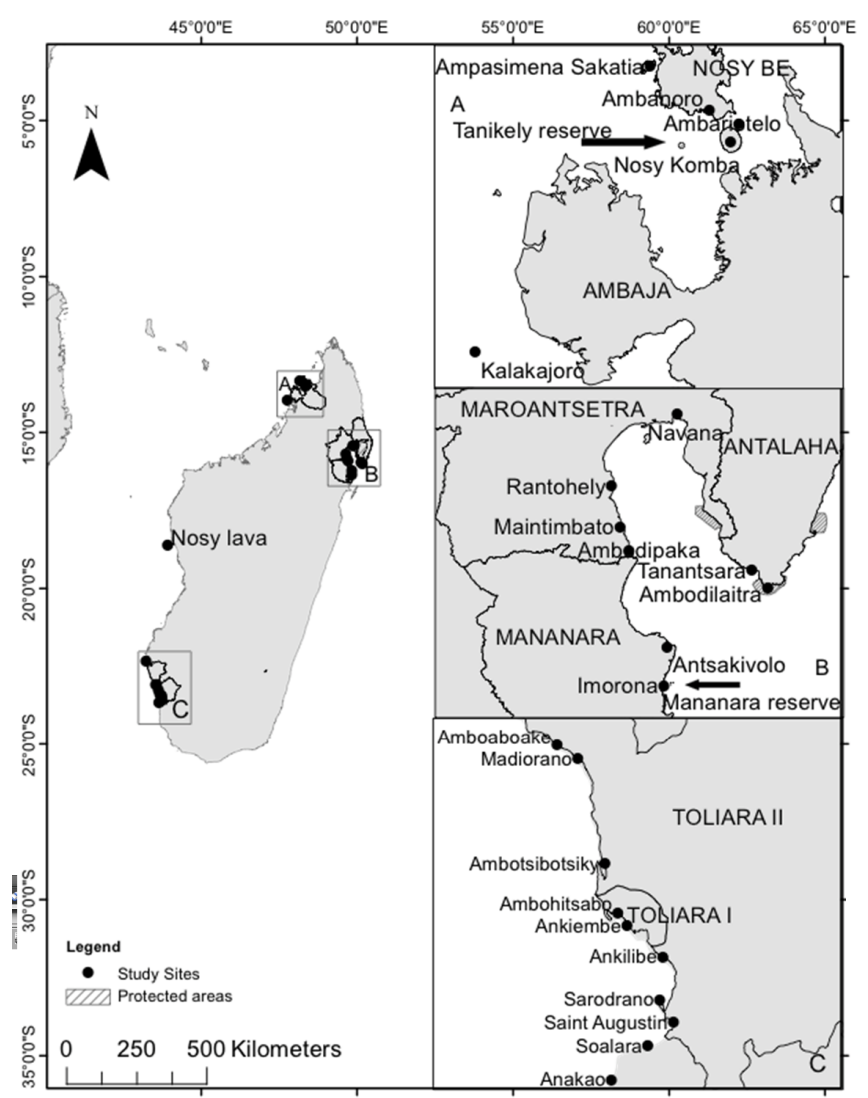

Ampasimena village, which is the second largest village after the town of Nosy Be. The island has seven villages, but the two main ones are Antanambe and Ampasimena, and the total population of these villages is approximately 500 . Fishing is not the main source of income; it is undertaken by only $19 \%$ of the population and is done to supplement the main economy, which is tourism. The marine and fisheries resources are managed under a community-based management structure called RASIS, which was formed by the French Initiative Cooperation in 2000 to reduce deforestation and promote tourism. RASIS is regulated by several dina rules (Rakotoson and Tanner 2006). Nosy Komba is a small volcanic island that supports lemurs and is an attraction for tourists. Consequently, the main economic activities include tourism and handicrafts, but other economic activities include boat building and the cultivation of crops such as rice, sugar cane for rum, and vanilla. The country's oldest fishery reserve, Tanikely Marine Reserve, is located nearby and is the main form of management. The villages of Ambarono and Ambariotelo were also sampled. Ambarano is a park village of approximately 2000 people, many who fish and are affected by the Tanikely Reserve. Ambariotelo is under the authority of a local queen who controls the use of natural resources through local taboo restrictions, including one that restricts visitors from other villages. Nevertheless, the rules are most frequently focused on the use of the forest. 
Table 1. Description of independent variables used in the analyses.

\begin{tabular}{llc}
\hline \hline Variable & Description & Data type \\
\hline Community decision-making & Whether respondent was involved in community decisions & Binary \\
Community organizations & Whether respondent was involved in community organizations & Binary \\
Migrant & Whether respondent was from the village or born somewhere else & Binary \\
Material lifestyle $1 \dagger$ & Principal component 1 from analysis & Continuous \\
Material lifestyle 2 & Principal component 2 from analysis & Continuous \\
Expenditures & Household's biweekly expenditures & Continuous \\
Education & Number of years of formal education & Continuous \\
Number of occupations & Number of different occupations in the household & Continuous \\
Age & Years of age & Continuous \\
Landing site & Landing site/village where the respondent lived & Nominal \\
\hline
\end{tabular}

$\dagger$ Material lifestyle is based on the status of the household wealth.

\section{METHODS}

\section{Field sampling methods}

Surveys of people's socioeconomic conditions and preferences for different types of fisheries management were conducted between 2008 and 2010 in 24 fishing villages (Fig. 1). A total of 519 individual surveys were completed using a mixture of interviews at landing sites and a generalized household survey (Table 1). Fishers were haphazardly sampled in the largest villages, but in smaller villages, the whole village was surveyed. In the larger villages, sampling followed the procedure of obtaining the names of fishers and their main gear use from village leaders, and interviewees were randomly selected in proportion to the gear use in the village.

We used a questionnaire described previously in which the interviewees are asked about their preferences for certain fisheries restrictions in terms of the sustainability of the resource and who benefits from the restriction (McClanahan et al. 2008). Interviewees were asked about their level of agreement with various management options on a five-point Likert scale. Interviewees were asked about their level of agreement with areabased management (marine protected areas), spatial closures, seasonal closures, restrictions on fishing gear, and limits on the minimum size and species captured. For each restriction, a question was asked using the following example format: "Do you believe that [spatial closures] are a good way to sustain fisheries?" Responses or levels of agreement were assessed as: agree completely, agree somewhat, neutral, disagree somewhat, and disagree completely; "do not know" was recorded separately and then dropped from the analyses. Then for each question, the interviewee was asked who benefits and by how much from these restrictions, with self, community, and government as possible answers, and benefits rated by marking an " $\mathrm{X}$ " on a 10-cm scale that ranged from no to high benefits. Additional socioeconomic and demographic questions examined respondents' age, education, livelihood options, material assets, expenditures, and their history of movement and employment (Cinner et al. 2009a).

Of the 519 interviews, a total of 465 interviews were sufficiently complete, clear, and error free for the subsequent statistical analyses. The largest problem was often weak comprehension of marine protected area (MPA) implementation and functions and how MPAs differ from spatial closures, and this question was therefore dropped from the analyses. The responses to benefits to self were most frequently understood and answered clearly and were, therefore, the basis for most of the subsequent analyses.

\section{Data analysis}

The material lifestyle score was based on the presence/absence of radio/cassette player and electricity in the specific household and an ordinal scale (bounded between 0 and 1) based on the quality of wall, roofing, and floor materials. For example, intermediate quality building materials such as a wooden plan floor was given a 0.5 , whereas higher quality materials such as concrete or metal were given a 1, and lower quality such as bush material was given a 0 . The final score was based on multiple variables and determined by conducting a principal component analysis using varimax rotation.

Hierarchal cluster analysis using the Ward method (JMP Statistics 5.0) based on the perceived benefit to self for five management restrictions was done on the villages' average responses to determine if there were distinct groups of villages with similarities in perceived benefits. This produced five clusters that we scaled from most to least positive. These cluster groups were the basis of subsequent analyses with socioeconomic and perceived benefits of management variables.

To determine relationships between our dependent variables (fishers' perceived benefits from the management options) and independent variables (fishers' socioeconomic conditions), we used three types of nonparametric statistical analysis, depending on the type of data (Table 1). Data were not normally distributed; thus, we used a Mann-Whitney U-test to test whether the mean rank of perceived benefits from the management options were different between our binary rankings such as between those that were involved in decision-making and those that were not. Further, we used Spearman rank correlation to determine whether levels of perceived benefits of the management options were correlated with continuous independent variables such as the number of different occupations in the household. We used the Kruskal-Wallis test to examine whether the ranks of fishers' perceived benefits were different between the different landing 
Table 2. Respondent characteristics showing sites, sample size, and mean \pm SE of age of respondent, level of education, biweekly expenditure, perceived mean disparity, and numbers of years in occupation. There are two coastal districts in the Toliara Province.

\begin{tabular}{|c|c|c|c|c|c|c|}
\hline $\begin{array}{l}\text { Region } \\
\text { District }\end{array}$ & Landing site & $\begin{array}{l}\text { Number of } \\
\text { respondents }\end{array}$ & $\begin{array}{c}\text { Age of } \\
\text { respondent (yr) }\end{array}$ & $\begin{array}{l}\text { Level of education } \\
\text { (yr) }\end{array}$ & $\begin{array}{c}\text { Biweekly expenditure } \\
\text { (Ariary) } \dagger\end{array}$ & $\begin{array}{c}\text { Number of years } \\
\text { in occupation }\end{array}$ \\
\hline \multicolumn{7}{|l|}{ Southwest-Toliara } \\
\hline Toliara 1 & Ankiembe & 31 & $33.0 \pm 1.9$ & $3.1 \pm 0.4$ & $73,548 \pm 4527$ & $17.7 \pm 2.0$ \\
\hline Toliara 1 & Ambohitsabo & 30 & $32.6 \pm 1.9$ & $5.8 \pm 0.4$ & $73,000 \pm 6559$ & $16.0 \pm 1.7$ \\
\hline Toliara 2 & Anakao & 30 & $32.5 \pm 1.5$ & $6.2 \pm 0.5$ & $65,667 \pm 1987$ & $16.2 \pm 1.8$ \\
\hline Toliara 2 & Saint Augustin & 30 & $40.4 \pm 2.6$ & $5.2 \pm 0.5$ & $77,500 \pm 5977$ & $25.8 \pm 2.7$ \\
\hline Toliara 2 & Sarodrano & 30 & $37.7 \pm 2.2$ & $5.9 \pm 0.7$ & $69,000 \pm 4230$ & $22.1 \pm 2.1$ \\
\hline Toliara 2 & Ankilibe & 60 & $34.6 \pm 1.9$ & $2.9 \pm 0.3$ & $71,662 \pm 4298$ & $20.2 \pm 1.8$ \\
\hline Toliara 2 & Soalara & 30 & $32.8 \pm 1.7$ & $4.8 \pm 0.4$ & $48,583 \pm 4835$ & $17.2 \pm 2.0$ \\
\hline \multicolumn{7}{|l|}{ Southwest-Ranobe } \\
\hline Toliara 2 & Amboaboake & 10 & $37.6 \pm 5.1$ & $2.6 \pm 0.8$ & $54,911 \pm 12,440$ & $22.9 \pm 5$ \\
\hline Toliara 2 & Ambotsibotsiky & 10 & $29.6 \pm 3.9$ & $1.5 \pm 0.6$ & $62,000 \pm 13,730$ & $20.3 \pm 3.3$ \\
\hline Toliara 2 & Madiorano & 10 & $39.7 \pm 5.6$ & $5.0 \pm 0.8$ & $44,375 \pm 9654$ & $24.1 \pm 4.3$ \\
\hline \multicolumn{7}{|c|}{ Northeast Antongil Bay } \\
\hline Antalaha & Ambodilaitra & 7 & $28.7 \pm 2.9$ & $4.3 \pm 1.1$ & $31,571 \pm 11,447$ & $9.4 \pm 2.4$ \\
\hline Mananara & Antsirakivolo & 5 & $35.8 \pm 7.2$ & $5.0 \pm 1.2$ & $31,000 \pm 6204$ & $11.2 \pm 3.9$ \\
\hline Mananara & Imorona & 20 & $38.9 \pm 2.7$ & $4.5 \pm 0.6$ & $53,500 \pm 16,055$ & $15.1 \pm 2.5$ \\
\hline Maroantsetra & Ambodipaka & 18 & $35.4 \pm 2.8$ & $4.7 \pm 0.5$ & $47,778 \pm 6693$ & $13.2 \pm 1.9$ \\
\hline Maroantsetra & Maintimbato & 10 & $40.6 \pm 2.9$ & $4.0 \pm 0.6$ & $27,500 \pm 1863$ & $12.8 \pm 3.0$ \\
\hline Maroantsetra & Navana & 8 & $32.6 \pm 2.6$ & $5.0 \pm 0.4$ & $21,875 \pm 1619$ & $11.25 \pm 2.6$ \\
\hline Maroantsetra & Rantohely & 25 & $35.6 \pm 1.6$ & $4.9 \pm 0.3$ & $75,800 \pm 7882$ & $9.8 \pm 0.8$ \\
\hline Maroantsetra & Tanantsara & 22 & $31.2 \pm 1.5$ & $5.0 \pm 0.3$ & $69,773 \pm 8543$ & $11.7 \pm 0.8$ \\
\hline \multicolumn{7}{|l|}{ Northeast } \\
\hline Hellville & Ambanoro & 30 & $38.8 \pm 1.5$ & $4.6 \pm 0.8$ & $47,167 \pm 12,716$ & $12.6 \pm 1.5$ \\
\hline Ambaja & Ambariotelo & 30 & $35 \pm 1.7$ & $4.6 \pm 0.7$ & $28,833 \pm 3944$ & $6.9 \pm 1.2$ \\
\hline Nosy Be & Ampasimena Sakatia & 29 & $35.1 \pm 1.9$ & $5.0 \pm 0.6$ & $31,879 \pm 3372$ & $12.0 \pm 1.8$ \\
\hline Nosy Be & Kalakajoro & 5 & $36.6 \pm 7.6$ & $2.0 \pm 1.3$ & $45,000 \pm 2236$ & $14.8 \pm 6.4$ \\
\hline Nosy Be & Nosy Komba & 30 & $37.6 \pm 1.8$ & $7.1 \pm 0.9$ & $42,000 \pm 12,725$ & $7.1 \pm 0.8$ \\
\hline \multirow[t]{2}{*}{ Nosy Be } & Nosy Lava & 10 & $38.3 \pm 4.1$ & $4.5 \pm 0.9$ & $43,000 \pm 6155$ & $\begin{array}{l}18.3 \pm 4.4 \\
\quad \# 160\end{array}$ \\
\hline & Grand total of fishers & 519 & $35.4 \pm 0.5$ & $4.7 \pm 0.1$ & $56,625 \pm 1805$ & $15.7 \pm 0.5$ \\
\hline
\end{tabular}

†USD \$1 2000 Ariary in 2009.

sites/villages. However, the question on protected areas was not included in the analysis because it was lacking one-half of responses. One-way ANOVA and post-hoc Tukey multiple comparisons were used to test for differences among the five response clusters.

\section{RESULTS}

\section{Socioeconomic characteristics}

Respondents were largely in their mid-30s, had approximately five years of education, had a biweekly expenditure of 56,000 Ariary (USD \$23), and had worked in their occupation for 16 years (Table 2). The principal component analysis of material lifestyle factors resulted in two factors that explain $64.5 \%$ of the variance (first component explains $43.1 \%$ ). Materials for the house structure loaded highly on factor 1 , whereas the presence of electricity and a radio loaded highly on component 2 (Table 3 ).

\section{Village perceptions of benefits}

Cluster analysis of the responses on perceived benefits of management restrictions to the fishers interviewed produced five distinct clusters for the villages, with three to six villages per cluster (Fig. 2). There was considerable mixing of villages between districts and regions and, although there was no clear distinction between villages based on the regions, the southwest rural villages were generally more moderate about benefits of restrictions to themselves than the more positive north region. Nevertheless, there were villages with relatively negative perceived benefits in Ambariotelo and Nosy Komba in the northwest and Antsirakivolo and Imorona in Mananara in the northeast.

Table 3. Rotated factor loadings from principal component analysis of the material lifestyle scores.

\begin{tabular}{lcc}
\hline \hline & \multicolumn{2}{c}{ Loadings } \\
\cline { 2 - 3 } Material lifestyle variable & Component 1 & Component 2 \\
\hline Wall materials & 0.892 & -0.003 \\
Roofing materials & 0.817 & 0.153 \\
Floor materials & 0.812 & 0.049 \\
Radio/cassette player & -0.084 & 0.850 \\
Electricity & 0.168 & 0.561 \\
\hline
\end{tabular}

Perceived sustainability of management restrictions for the five village clusters for each restriction indicated significant differences between village clusters for all restrictions except for gear restrictions, which were viewed positively by all village clusters (Fig. 3). Restrictions on gear, closed areas and seasons, 
Fig. 2. Hierarchical cluster analysis (Ward method) based on fishers' ratings of personal benefits from the five management restrictions. Clusters are numbered from the most to least positive rating of restrictions. These five cluster groups were used in subsequent analyses. The government districts of the sampled landing sites are shown in the legend.

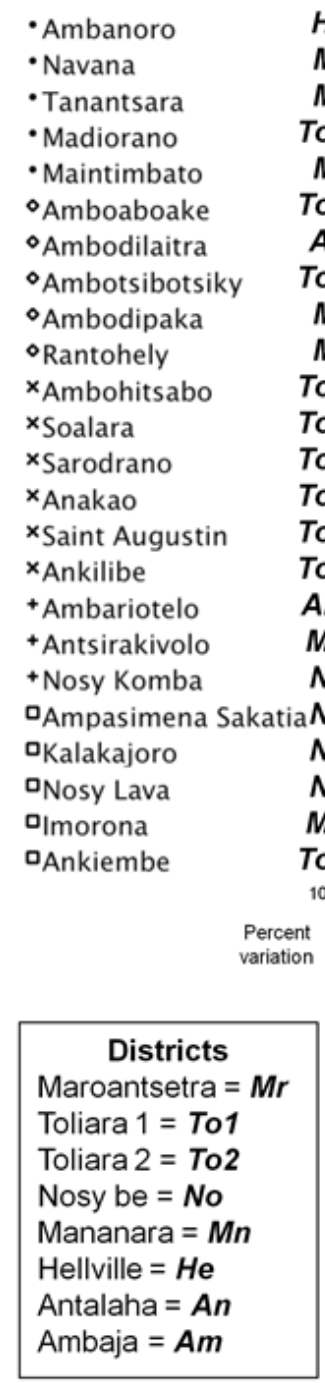

and minimum size of fish were scaled highly but with some differences among clusters and villages (Fig. 3 ). The sustainability of closed areas was similar for most groups, but scaled very positive for the most positive villages. Species selection was only slightly positive for the two most positive village clusters.

The perceived benefit of restrictions to the fishers themselves were generally positive, with the exception of restrictions on species, for which only the two most positive clusters agreed that species restrictions would benefit themselves and promote sustainability (Figs. 3 and 4). Fishers that did not support species restrictions believed that all species should be used (Table 4). Gear restrictions were the most positive for sustainability and personal benefits, and the most common reasons given for these benefits were conservation and ease of enforcement. Changes in catch, breeding, conservation, and reduced fishing grounds were often given as reasons for and against closed areas, closed seasons, and minimum fish length restrictions.

\section{Socioeconomic associations}

There were statistical differences in the social metrics of the clusters with the exception of the fisher's age (Table 5). However, these differences did not follow clear gradients along the scaling of clusters from least to most positive. Nevertheless, when evaluating the patterns at the level of respondent, there were more significant associations (Table 6). Specifically, fishers involved in community decision-making had a higher scaling of perceived benefits to themselves from closed areas, closed seasons, and species restrictions, but lower scaling of gear restrictions (Table 6). Fishers involved in community organizations scaled perceived benefits for closed seasons low but species restrictions high. Migrant fishers scaled species restriction benefits to themselves low.

Table 4. Common reasons for agreement and disagreement with various management options. Number of responses is in parentheses.

\begin{tabular}{lll}
\hline \hline $\begin{array}{l}\text { Management } \\
\text { option }\end{array}$ & Disagree completely & Agree completely \\
\hline Closed areas & $\begin{array}{l}\text { 1. Not beneficial } \\
\text { 2. Reduced fishing ground }\end{array}$ & 1. Improved catch (76) \\
Closed seasons & N/A & $\begin{array}{l}\text { 1. Breeding season (292) } \\
\text { 2. Conservation (48) }\end{array}$ \\
Gear restriction & 1. Gear protection (12) & $\begin{array}{l}\text { 1. Conservation (83) } \\
\text { 2. Enforcement (83) }\end{array}$ \\
& & $\begin{array}{l}\text { 3. Beneficial? (52) } \\
\text { 4. Opinion differs (59) }\end{array}$ \\
$\begin{array}{lll}\text { Minimum fish } \\
\text { size }\end{array}$ & N/A & 1. Conservation (40) \\
Species selection & 1. All species are important & 1. Food web balance (21) \\
& for use (91) & \\
\hline & 2. Not beneficial (21) &
\end{tabular}

Fishers' material lifestyle metrics associated with the material permanency of their houses were positively associated with their support for closed areas and species restrictions. Species restrictions and closed seasons were negatively associated with the second material lifestyle axis, which indicates more support for these restrictions with higher house permanency but not with the electrification of their houses and ownership of a radio. Education was low overall and had no association apart from weak positive support for gear restrictions. The respondent's number of occupations was positively associated with all restrictions, with older fishers more supportive of closed areas and species restrictions.

\section{DISCUSSION}

The stated support for personal benefits and perceived sustainability arising from management restrictions in Madagascar's coastal villages was generally strong and widespread. There were no clear differences at the regional levels that might suggest that the scaling of management was related to regional or climatic environments. For example, people living in 
Fig. 3. Fishers' ratings (mean \pm SE) of the perceived sustainability of five proposed management restrictions analyzed for five village clusters, based on fishers' perceived personal benefits from the restriction. Results of nested ANOVA for tests of differences between clusters and nested villages are given for each restriction.

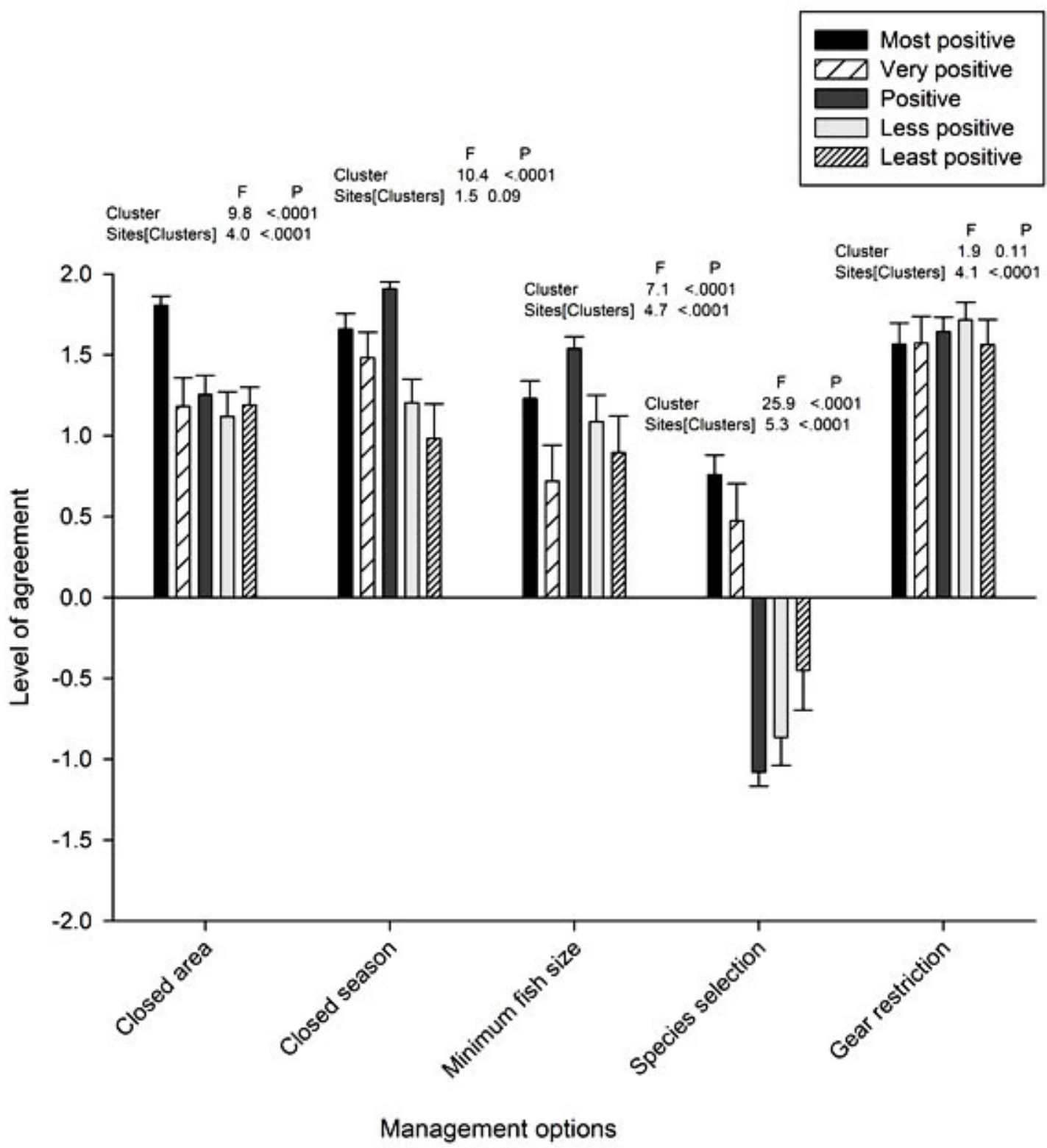

the southwest region live in a dry climate with high reliance on fishing, whereas the climate in the northeast is wet and there is more dependence on farming, yet we found no evidence that the climatic conditions produced strong differences in perceptions. The Vezo people interviewed in the southwest region strongly associate with the maritime activities to the extent that the definition of their ethnicity is the action of doing maritime activities rather than a definition based on genetics or place of origin (Astuti 1995). Vezo are described as being defiant to concepts of kinship ties and have historically avoided efforts to be attached to kin origins, which they see as potentially oppressive to their autonomy and lifestyle. In contrast, ancestry and connections to past relatives is reported to be a critical part of people's identity around Antongil Bay, where the main ethnic group is Betsimisaraka (Keller 2008). Those Antongil Bay people who are descended from slaves are reported to be trying to restore a permanent kinship and attachment to kin by establishing 
Table 5. Summary of key descriptions (mean \pm SE) of the respondents in the three clusters of management preferences and one-way ANOVA test of significance. The material lifestyle metric is a multivariate principal component analysis scaling based on ownership of various household items; positive values indicate greater material assets and vice versa. Different uppercase letters indicate significant differences among clusters based on post-hoc Tukey multiple comparisons.

\begin{tabular}{|c|c|c|c|c|c|}
\hline & $\begin{array}{c}\text { Number of years in } \\
\text { occupation }\end{array}$ & $\begin{array}{c}\text { Perceived mean } \\
\text { benefit }\end{array}$ & $\begin{array}{c}\text { Age of respondent } \\
(\mathrm{yr})\end{array}$ & $\begin{array}{c}\text { Level of education } \\
(\mathrm{yr})\end{array}$ & $\begin{array}{c}\text { Biweekly expenditure } \\
(\text { Ariary }) \dagger\end{array}$ \\
\hline \multicolumn{6}{|l|}{ Cluster } \\
\hline Most positive & $13.9 \pm 1.2 \mathrm{~B}$ & $0.5 \pm 0.1 \mathrm{~B}$ & $38.4 \pm 1.6 \mathrm{~A}$ & $4.4 \pm 0.5 \mathrm{~B}$ & $39,464 \pm 7052$ В \\
\hline Very positive & $13.4 \pm 0.9 \mathrm{~B}$ & $5.1 \pm 0.3 \mathrm{~A}$ & $33.6 \pm 1.1 \mathrm{~A}$ & $4.2 \pm 0.2 \mathrm{AB}$ & $61,100 \pm 3978 \mathrm{~A}$ \\
\hline Positive & $19.7 \pm 0.9 \mathrm{~A}$ & $0.3 \pm 0.1 \mathrm{~A}$ & $35.0 \pm 0.9 \mathrm{~A}$ & $4.8 \pm 0.2 \mathrm{~A}$ & $67,713 \pm 2057 \mathrm{~A}$ \\
\hline Less positive & $7.34 \pm 0.7 \mathrm{~B}$ & $-0.3 \pm 0.1 \mathrm{~A}$ & $36.3 \pm 1.3 \mathrm{~A}$ & $5.8 \pm 0.5 \mathrm{AB}$ & $35,076 \pm 6160 \mathrm{~A}$ \\
\hline Least positive & $15.4 \pm 1.2 \mathrm{C}$ & $-1.2 \pm 0.1 \mathrm{C}$ & $35.6 \pm 1.2 \mathrm{~A}$ & $4.0 \pm 0.3 \mathrm{~B}$ & $52,122 \pm 4231 \mathrm{C}$ \\
\hline \multicolumn{6}{|l|}{ ANOVA } \\
\hline$N$ & 465 & 465 & 465 & 464 & 465 \\
\hline $\mathrm{R}^{2}$ & 0.14 & 0.30 & 0.01 & 0.03 & 0.14 \\
\hline F ratio & 18.36 & 49.4 & 1.73 & 3.69 & 18.02 \\
\hline$P$ & $<0.0001$ & $<0.0001$ & 0.14 & 0.0057 & $<0.0001$ \\
\hline
\end{tabular}

$\dagger$ USD \$1 2000 Ariary in 2009.

Fig. 4. Mean (SD) perceived personal benefit for each management restriction presented for the five village clusters (Fig. 2). A score of 10 indicates the maximum benefit. Results of ANOVA for differences between village clusters are given.
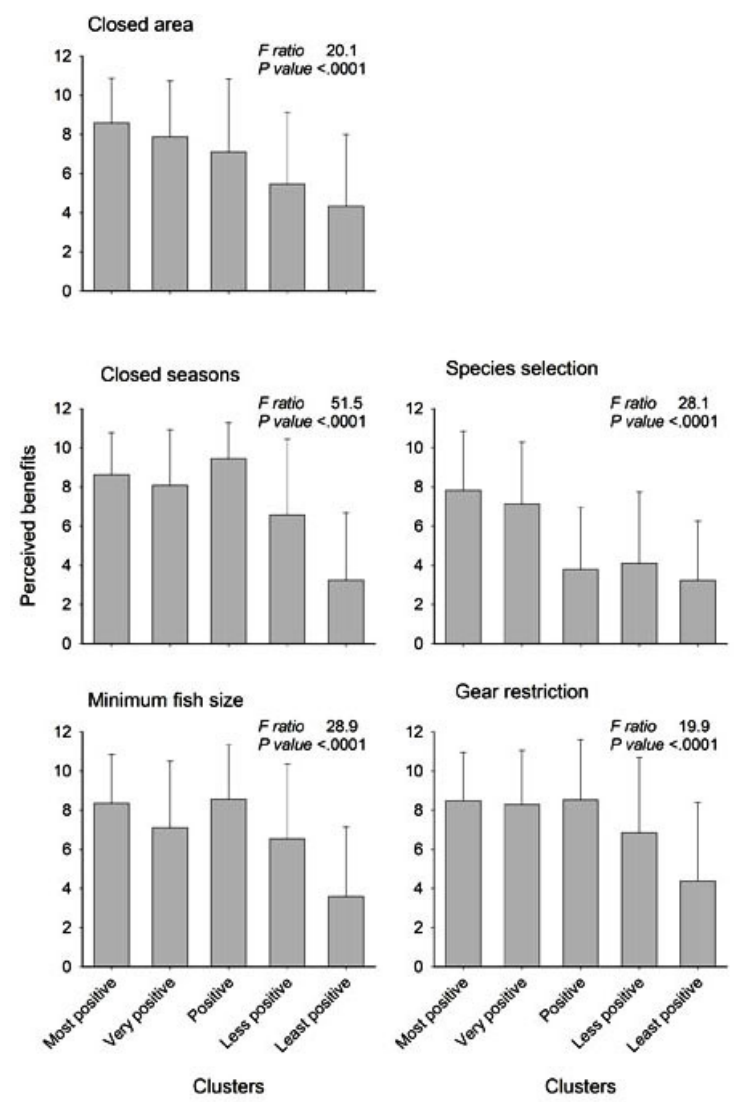

permanent grave sites where kin are buried and will be identified in the future as a place of origin. Thus, kinship and ancestry is a critical part of their culture, and the expansion of kin is seen as fulfilling the wishes of their ancestors and the purpose of life.

While the above indicates that there are at least two very divergent views of ethnicity and culture in Madagascar, these are not strongly associated with stated preferences for fisheries restrictions. Both of these core cultural views may, however, run into conflict with resource management restrictions, but for very different reasons. The Vezo view of their right to use the sea, and some Antongil Bay people's view of their right to increase kin and human population density, can both conflict with resource management and environmental agendas. Iida (2005) described the Vezo as being aware of the resource decline, but their response was to increase migratory fishing rather than increase local management restrictions. Keller (2008) describes farmers around Antongil Bay as feeling defeated in life's purpose by proposed forest management restrictions. The sum of these reports exposes an irony that if these views and responses to management are pervasive, regardless of the underlying causes, then why is there considerable and generally widespread favor toward fisheries management restrictions? Could this arise from the complexities of context in which people evaluate their values and decisions and respond to questions?

Investigations into respondent bias conclude that there are cultural bias effects on value-type questions that can reflect core cultural elements (Smith 2004, Fischer et al. 2009). Respondents may see management restrictions as socially desirable, may profess favor if they perceive the interviewee to be in favor of the restrictions, or may have an overall culture of acquiescence when answering questions regardless of the content of the question. A positive acquiescence style has been associated with countries with high income inequality, poverty, collectivistic social organization, feminine values, low power distance, and low stability in governance and civil rights (Fischer et al. 2009). These personality and cultural metrics have not been studied specifically for Madagascar, but some of these elements, particularly poverty, 
Table 6. Levels of significance† for the relationships between socioeconomic factors and perceived benefits to self for different management options based on principal components analysisł.

\begin{tabular}{|c|c|c|c|c|c|}
\hline & Closed areas & Closed seasons & $\begin{array}{l}\text { Minimum fish } \\
\text { size }\end{array}$ & $\begin{array}{c}\text { Species } \\
\text { restriction }\end{array}$ & Gear restriction \\
\hline Community decision-making (1) & 0.001 & 0.001 & 0.07 & 0.001 & $0.006(-)$ \\
\hline Community organizations (1) & 0.30 & $0.001(-)$ & 0.054 & 0.001 & 0.21 \\
\hline Migrant (1) & 0.87 & 0.27 & 0.37 & $0.001(-)$ & 0.39 \\
\hline Material lifestyle 1 (2) & 0.026 & 0.76 & 0.72 & 0.094 & 0.11 \\
\hline Material lifestyle 2 (2) & $0.001(-)$ & $0.011(-)$ & 0.33 & $0.001(-)$ & 0.78 \\
\hline Expenditures (2) & 0.19 & 0.001 & 0.001 & $0.001(-)$ & 0.007 \\
\hline Education (2) & 0.23 & 0.63 & 0.69 & 0.25 & 0.05 \\
\hline Number of occupations (2) & 0.002 & 0.013 & 0.001 & 0.001 & 0.001 \\
\hline Age (2) & 0.011 & 0.49 & 0.48 & 0.043 & 0.78 \\
\hline Landing site (3) & 0.001 & 0.001 & 0.001 & 0.001 & 0.001 \\
\hline
\end{tabular}

$\dagger P$ values.

$\downarrow$ Relationships are positive unless indicated in parentheses.

weak and unstable civil governments, and collective organization, are clearly present in this country and in the broader region (Schmitt et al. 2007, Hofstede et al. 2010). Additionally, Pollnac et al. (2010) found that Malagasy were likely overestimating compliance with marine reserves. Nevertheless, not all aspects of the responses suggest acquiescence because many respondents clearly listed benefits of restrictions as a greater benefit to themselves than the government, which suggests that perceived social desirability at the government scale is less than the personal consideration of the benefit. Consequently, if there is an acquiescent element it is not pervasive to all scales of governance or all restrictions. There was variation in the responses to specific restrictions that suggests that, if there were a bias, it largely influenced absolute and not relative scaling of the restrictions. Overall, the country-level biases of response styles are small unless Madagascar is a rarity to the overall patterns (Fischer et al. 2009).

There were, however, elements of culture and familiarity in responses such as those for area-based management questions, for which many people had difficulty distinguishing area-based management from closures or other more specific restrictions. Dina management is usually based on $f a d y$, which are specific taboo restrictions that are generally clear and distinct and often associated with certain individuals or families, and largely selfenforced. It is possible that people were not familiar with management based on multiple-use zoning (i.e., where activities such as tourism, net fishing, line fishing, etc. are permitted in specific zones) because it does not have a strong cultural precedence. Thus, some people may have simply not had the context to understand the question. This was, however, not universal, and the Masoala National Marine Park in the northeast composes three zones of closures, gear restrictions, and open access (Kremen et al. 1999). Cinner et al. (2009b,c) describe fady as a latent form of management, but state that it can be undermined by lack of trust, inflexible institutions, poverty, inadequate social-ecological feedbacks, and the lack of a mechanism to implement graduated sanctions. In a low enforcement capacity context such as Madagascar, successful management largely depends on understanding the social and institutional conditions that facilitate self-compliance (Cinner et al. 2012b).

The strongest differences in management preferences were found at the village and cluster levels, which were not clearly associated with socioeconomic variables at this aggregate level of analysis. For example, education and expenditures were not significant at this level of respondent aggregation. Given that all respondents were poor and with primary school levels of education, this may have produced low heterogeneity and subsequent weak gradients among clusters and villages. Consequently, we believe that differences in villages and clusters were more likely to represent local village histories rather than income and education. For example, the histories of fishers' associations with the Mananara Reserve in the northeast and possibly the Tanikely Marine Reserve management or royalty decision-making in the areas of Ambariotelo and Nosy Komba may be responsible for the negative perceptions of benefits in these villages. Indeed, this interpretation is broadly consistent with a body of anthropological and sociological literature that examines how perceptions about conservation are influenced by local cultural context and history (Keller 2008).

At the level of individual fishers, there were more socioeconomic associations with management perceptions. Generally, respondents who were involved in community decision-making, were older, had additional or alternate employment, and were living in more permanent structures had more positive perceptions of the personal benefits of management restrictions. Consequently, there are some elements of knowledge and wealth that promote stronger opinions that might result in great acknowledgement of benefits to themselves or the community. This was, however, not true for all restrictions, as those involved in decision-making and community organization rated some restrictions such as closed seasons and gear restrictions as not personally beneficial. This may represent some experience with restrictions within their communities, in that there may be no individual benefit if, for example, the restrictions were not adopted or not followed by all people and therefore no management benefits were observed. This 
may also explain some of the more negative views in communities around the two areas with marine reserves. In general, when respondents questioned the sustainability of the restrictions, they also perceived little benefit to themselves.

Given the poverty and sparse history of national fisheries management implementation (Le Manach et al. 2012), the high rating of management restrictions was unexpected. There are a number of likely explanations for this support including: (1) a widespread recognition of the need for restrictions, (2) lack of experience with fishing restrictions and negative personal effects of these restrictions, (3) acquiescence with suggested restrictions, (4) widespread acceptance of cultural and personal taboos and restrictions, and (5) a stated normative preference but not necessarily a willingness to comply with restrictions once implemented. Clearly, all of these can play a role, and a better understanding of the causes of these perceptions is needed to evaluate their various roles.

Experience with management can promote both positive and negative perceptions depending on specific outcomes and socioeconomic aspects of those affected (Cinner et al. 2012b). For example, a study of the controversial Mafia Island marine protected area in Tanzania found that the polarized views were influenced by fishers' dependence on fishing and sources of alternative livelihoods; fishers most reliant on marine resources had negative views whereas those with other livelihood alternatives had positive views (McClanahan et al. 2008). Similarly, views were positive toward protected areas in Kenya among those living close to but not those living far from government-managed closures, and positive views increased with time since MPA establishment (McClanahan et al. 2005, 2012). Consequently, the weak heterogeneity of perceptions in Madagascar may represent a lack of experience, given the few protected areas and weak implementation of national fisheries restrictions.

LeManach et al. (2012) described the widespread, heavy use of marine resources and declining production at the national level in Madagascar. Similarly, a number of studies of terrestrial parks have found increased poverty and marginalization of people living near them (Walsh 2012). Thus, people's perceptions about fisheries management restrictions is expected to change if proposed systems of marine spatial planning are implemented (Allnut et al. 2012). The considerable self- and community reliance of resource users, the weak history of national governance, and current funding of Madagascar National Parks from foreign donors creates some challenges for implementing management, but several policy implications emerged from this study that may be helpful. First, there are some restrictions, such as those on gear, that are likely to have broad appeal and may gain widespread support and possibly succeed if implemented at the national level. Other restrictions such as closed seasons and minimum size of fish are more likely to be adopted among the villages found in the three most positive village clusters, while closures may only have strong early support in the most positive cluster villages. Restrictions on species are not likely to find support at the either the national or most local levels, and an early focus on species restrictions is expected to lead to conflict and undermine management dialogs and plans.

International donor and conservation groups often prefer restrictions on species and closures. This disparity in preference and focus is expected to lead to difficulties and slow progress unless targeted at those specific villages and resource users with the most positive views toward these specific restrictions. Consequently, we advocate an approach that takes advantage of the scales of agreement and perceptions, proceeds from the most to least widely accepted restrictions, and targets restrictions to the spatial scale of the agreement as management developments and influence spread.

Second, the individual-level analysis of preferences suggests that there are a number of social correlates that may also promote greater support for or opinions about management restrictions. These are involvement in decision-making, experienced people, livelihood alternatives, and permanent living conditions. These help to identify socioeconomic targets for implementing restrictions that are holistic in addressing the social-ecological system. These can be looked for and built on or developed along with the management plans and implementation. Cinner et al. $(2009 c)$ outlined the socioeconomic needs for protected area development and emphasized infrastructure, livelihoods, education, local empowerment, and building trust. Iida (2005) and Bruggemann et al. (2012) both describe the complexity of the problems and the need for forums where the problems and potential solutions can be discussed. Working with, rather than against, selfish perceptions may lead to progress that has been slow to develop but is now greatly needed in Madagascar.

\section{Responses to this article can be read online at: http://www.ecologyandsociety.org/issues/responses. $\mathrm{php} / 6080$}

\section{Acknowledgments:}

This research was supported by the MASMA (Marine Science for Management) program of the WIOMSA (Western Indian Ocean Marine Science Association) and the Catherine T. and John D. MacArthur Foundation. We are grateful for the logistic support provided by Lisa Gaylord, Chris Holmes, Herilila Randriahmahazo, Ravo, Wildlife Conservation Society country program office, and we thank Pascal Thoya for producing the map.

\section{LITERATURE CITED}

Adams, W. M., D. Brockington, J. Dyson, and B. Vira. 2003. Managing tragedies: understanding conflict over common pool resources. Science 302:1915-1916. http://dx.doi.org/10.1126/ science. 1087771

Allnut, T. F., T. R. McClanahan, S. Andréfouët, M. Baker, E. Lagabrielle, C. McClennen, A. J. M. Rakotomanjaka, T. F. Tianarisoa, R. Watson, and C. Kremen. 2012. Comparison of marine spatial planning methods in Madagascar demonstrates value of alternative approaches. PLOS One 7(2): e28969. http:// dx.doi.org/10.1371/journal.pone.0028969

Astuti, R. 1995. "The Vezo are not a kind of people": identity, difference, and "ethnicity" among a fishing people of western Madagascar. American Ethnologist 22(3):464-482. http://dx.doi. org/10.1525/ae.1995.22.3.02a00010 
Béné, C., E. Belal, M. O. Baba, S. Ovie, A. Raji, I. Malasha, F. Njaya, M. N. Andi, A. Russell, and A. Neiland. 2009. Power struggle, dispute and alliance over local resources: analyzing 'democratic' decentralization of natural resources through the lenses of Africa inland fisheries. World Development 37 (12):1935-1950. http://dx.doi.org/10.1016/j.worlddev.2009.05.003

Bruggemann, J. H., M. Rodier, M. M. M. Guillaume, S. Andrèfouît, R. Arfi, J. E. Cinner, M. Pichon, F. Ramahatratra, F. Rasoamanendrika, J. Zinke, and T. R. McClanahan. 2012. Wicked social-ecological problems forcing unprecedented change on the latitudinal margins of coral reefs: the case of southwest Madagascar. Ecology and Society 17(4): 47. http://dx.doi. org/10.5751/ES-05300-70447

Cinner, J. E., T. Daw, and T. R. McClanahan. 2009a. Socioeconomic factors that affect artisanal fishers' readiness to exit a declining fishery. Conservation Biology 23(1):124-130. http://dx.doi.org/10.1111/j.1523-1739.2008.01041.x

Cinner, J. E., T. M. Daw, T. R. McClanahan, N. Muthiga, C. Abunge, S. Hamed, B. Mwaka, A. Rabearisoa, A. Wamukota, E. Fisher, and N. Jiddawi. 2012a. Transitions toward comanagement: the process of marine resource management devolution in three east African countries. Global Environmental Change 22(3):651-658. http://dx.doi.org/10.1016/j.gloenvcha.2012.03.002

Cinner, J., M. M. P. B. Fuentes, and H. Randriamahazo. $2009 b$. Exploring social resilience in Madagascar's marine protected areas. Ecology and Society 14(1): 41. [online] URL: http://www. ecologyandsociety.org/vol14/iss1/art41/.

Cinner, J. E., T. R. McClanahan, M. A. MacNeil, N. A. J. Graham, T. M. Daw, A. Mukminin, D. A. Feary, A. L. Rabearisoa, A. Wamukota, N. Jiddawi, S. J. Campbell, A. H. Baird, F. A. Januchowski-Hartley, S. Hamed, R. Lahari, T. Morove, and J. Kuange. 2012b. Comanagement of coral reef social-ecological systems. Proceedings of the National Academy of Sciences 109 (14):5219-5222. http://dx.doi.org/10.1073/pnas.1121215109

Cinner, J. E., A. Wamukota, H. Randriamahazo, and A. Rabearisoa. 2009c. Toward institutions for community-based management of inshore marine resources in the western Indian Ocean. Marine Policy 33(3):489-496. http://dx.doi.org/10.1016/j. marpol.2008.11.001

Cooke, A. 2003. Marine and coastal ecosystems of Madagascar. Pages 179-208 in S. M. Goodman and J. P. Benstead, editors. The natural history of Madagascar. Chicago University Press, Chicago, Illinois, USA.

Doukakis, P., M. Jonahson, V. Ramahery, B. J. de Dieu Randriamanantsoa, and S. Harding. 2008. Traditional fisheries of Antongil Bay, Madagascar. Western Indian Ocean Journal of Marine Science 6(2):175-181. http://dx.doi.org/10.4314/wiojms. v6i2.48237

Fischer, R., J. R. J. Fontaine, F. J. R. van de Vijver, and D. A. van Hemert. 2009. An examination of acquiescent response styles in cross-cultural research. Pages 137-147 in A. Gari and K. Mylonas, editors. Quod erat demonstrandum: from Herodotus' ethnographic journeys to cross-cultural research. International Association for Cross-cultural Psychology, Athens, Greece. [online] URL: http:// www.iaccp.org/drupal/node/413.
Gabrié, C., P. Vasseur, H. Randriamiarana, J. Maharavo, and E. Mara. 2000. The coral reefs of Madagascar. Pages 411-444 in T. R. McClanahan, C. R. C. Sheppard, and D. O. Obura, editors. Coral reefs of the Indian Ocean: their ecology and conservation. Oxford University Press, Oxford, UK.

Harris, A., G. Manahira, A. Sheppard, C. Gough, and C. Sheppard. 2010. Demise of Madagascar's once great barrier reef: changes in coral reef conditions over 40 years. Atoll Research Bulletin 574. Smithsonian Institution Press, Washington, D.C., USA. [online] URL: http://si-pddr.si.edu/dspace/handle/10088/8936. http://dx.doi.org/10.5479/si.00775630.574.16

Hofstede, G., Hofstede, G. J. and M. Minkov. 2010. Cultures and organization: software of the mind: intercultural cooperation and its importance for survival. McGraw Hill, New York, New York, USA.

Horning, N. R. 2005. The cost of ignoring rules: forest conservation and rural livelihood outcomes in Madagascar. Forests, Trees and Livelihoods 15(2):149-166. http://dx.doi. org/10.1080/14728028.2005.9752517

Jentoft, S., and T. Kristoffersen. 1989. Fishermen's comanagement: the case of the Loftoten fishery. Human Organization 48(4):355-365.

Keller, E. 2009. The danger of misunderstanding 'culture'. Madagascar Conservation \& Development 4(2):82-85. [online] URL: http://www.mwc-info.net/en/services/Journal_PDF's/Issue4-2/ MCD 2009 vol4 iss2 culture.pdf. http://dx.doi.org/10.4314/mcd. $\underline{\mathrm{v} 4 \mathrm{i} 2.48647}$

Keller, E. 2008. The banana plant and the moon: conservation and the Malagasy ethos of life in Masoala, Madagascar. American Ethnologist 35(4):650-664. http://dx.doi.org/10.1111/ j.1548-1425.2008.00103.x

Kremen, C., V. Razafimahatratra, R. P. Guillery, J. Rakotomalala, A. Weiss, and J.-S. Ratsisompatrarivo. 1999. Designing the Masoala National Park in Madagascar based on biological and socioeconomic data. Conservation Biology 13(5):1055-1068. http://dx.doi.org/10.1046/j.1523-1739.1999.98374.x

Laroche, J., J. Razanoelisoa, E. Fauroux, and M. W. Rabenevanana. 1997. The reef fisheries surrounding the southwest coastal cities of Madagascar. Fisheries Management and Ecology 4(4):285-299. http://dx.doi.org/10.1046/j.1365-2400.1997.00051. $\underline{\mathrm{X}}$

Le Manach, F., C. Gough, A. Harris, F. Humber, S. Harper, and D. Zeller. 2012. Unreported fishing, hungry people and political turmoil: the recipe for a food security crisis in Madagascar? Marine Policy 36(1):218-225. http://dx.doi.org/10.1016/j. marpol.2011.05.007

Iida, T. 2005. The past and present of the coral reef fishing economy in Madagascar: implications for self-determination of resource use. Senri Ethnological Studies 67:237-258.

McClanahan, T. R., C. A. Abunge, and J. E. Cinner. 2012. Heterogeneity in fishers' and managers' preferences towards management restrictions and benefits in Kenya. Environmental Conservation 39(4):357-369. http://dx.doi.org/10.1017/S0376892912000197 
McClanahan, T. R., M. Ateweberhan, J. Omukoto, and L. Pearson. 2009. Recent seawater temperature histories, status, and predictions for Madagascar's coral reefs. Marine Ecology Progress Series 380:117-128. http://dx.doi.org/10.3354/meps07879

McClanahan, T. R., J. Cinner, A. T. Kamukuru, C. Abunge, and J. Ndagala. 2008. Management preferences, perceived benefits and conflicts among resource users and managers in the Mafia Island Marine Park, Tanzania. Environmental Conservation 35:340-350. http://dx.doi.org/10.1017/S0376892908005250

McClanahan, T. R., J. Davies, and J. Maina. 2005. Factors influencing resource users and managers' perceptions towards marine protected area management in Kenya. Environmental Conservation 32:42-49. http://dx.doi.org/10.1017/S0376892904001791

Nadon, M. O., D. Griffiths, E. Doherty, and A. Harris. 2007. The status of coral reefs in the remote region on Andavadoaka, southwest Madagascar. Western Indian Ocean Journal of Marine Science 6(2):207-218. http://dx.doi.org/10.4314/wiojms.v6i2.48244

Ostrom, E. 1990. Governing the commons: the evolution of institutions for collective action. Cambridge University Press, Cambridge, UK. http://dx.doi.org/10.1017/CBO9780511807763

Pollnac, R., P. Christie, J. E. Cinner, T. Dalton, T. M. Daw, G. E. Forrester, N. A. J. Graham, and T. R. McClanahan. 2010. Marine reserves as linked social-ecological systems. Proceedings of the National Academy of Sciences 107(43):18262-18265. http://dx. doi.org/10.1073/pnas.0908266107

Pomeroy, R. S., and F. Berkes. 1997. Two to tango: the role of government in fisheries co-management. Marine Policy 21 (5):465-480. http://dx.doi.org/10.1016/S0308-597X(97)00017-1

Rakotoson, L. R., and K. Tanner. 2006. Community-based governance of coastal zone and marine resources in Madagascar. Ocean \& Coastal Management 49(11):855-872. http://dx.doi. org/10.1016/j.ocecoaman.2006.08.003

Schmitt, D. P., J. Allik, R. R. McCrae, and V. Benet-Martinez. 2007. The geographic distribution of big five personality traits: patterns and profiles of human self-description across 56 nations. Journal of Cross-Cultural Psychology 38(2):173-212. http://dx. doi.org/10.1177/0022022106297299

Smith, P. B. 2004. Acquiescent response bias as an aspect of cultural communication style. Journal of Cross-Cultural Psychology 35(1):50-61. http://dx.doi.org/10.1177/0022022103260380

Sutinen, J. G., and K. Kuperan. 1999. A socio-economic theory of regulatory compliance. International Journal of Social Economics 26(1-3):174-193. http://dx.doi.org/10.1108/03068299910229569

Wade, R. 1994. Village republics: economic conditions for collective action in south India. ICS Press, San Francisco, California, USA.

Walsh, A. 2012. Made in Madagascar: sapphires, ecotourism and the global bazaar. University of Toronto Press, Toronto, Canada.

World Bank. 2013. Madagascar country environmental analysis: taking stock and moving forward. World Bank, Washington, D.C., USA. 